\title{
Media Reporting on Air Pollution: Health risk and precautionary measures in national and regional newspapers
}

\section{Steven Ramondt ( $\nabla$ s.ramondt@vu.nl )}

Vrije Universiteit Amsterdam https://orcid.org/0000-0001-6794-6894

\section{A. Susana Ramirez}

University of California Merced

\section{Research article}

Keywords: Air pollution, Environment health, Public health, Newspapers, Environmental health literacy, Health promotion, Health communication, Efficacy, Risk communication, Advocacy

Posted Date: March 2nd, 2020

DOI: https://doi.org/10.21203/rs.3.rs-15562/v1

License: (c) (i) This work is licensed under a Creative Commons Attribution 4.0 International License. Read Full License

Version of Record: A version of this preprint was published at International Journal of Environmental Research and Public Health on September 7th, 2020. See the published version at https://doi.org/10.3390/ijerph17186516. 
Media reporting on air pollution:

2

3

4

5

6

7

8

9

10

11

12

13

14 Corresponding author at:

15 University of California, Merced

16 SSHA, Psychological Sciences

175200 North Lake Road

$18 \quad$ Merced, CA 95343

19 United States of America

20 sramondt@ucmerced.edu

21

22

23
Steven Ramondt ${ }^{1}$ and A. Susana Ramírez ${ }^{2}$

${ }^{1}$ Psychological Sciences, University of California, Merced, CA, USA

${ }^{2}$ Public Health, University of California, Merced, CA, USA 


\section{Abstract}

\section{Background}

Exposure to air pollution is one of the primary global health risk factors, yet individuals lack the knowledge to engage in individual risk mitigation and the skills to mobilize for change necessary to reduce such risks. The news media are an important tool for influencing individual actions and support for public policies to reduce environmental threats; thus, a lack of news coverage of such issues may exacerbate knowledge deficits. This study examines the reporting of health risk and precautionary measures regarding air pollution in national and regional print news using an environmental health literacy perspective.

\section{Methods}

We conducted a content analysis of two national (New York Times and Washington Post) and two local newspapers (Fresno Bee and Bakersfield Californian) newspapers covering the country's most polluted region, California's San Joaquin Valley, during a 5-year period (20112015). Using a constructed week sampling approach, 276 newspaper articles were coded for information on threat, efficacy information, and information sources.

\section{Results}

News coverage of air pollution mostly failed to mention human health risks. Moreover, fewer than 10 percent of news stories about air pollution provided information on the precautionary measures necessary for individuals to take action to mitigate their risk. Despite being located in one of the most polluted areas in the US, local newspapers did not report significantly more threat and efficacy information. News coverage of air pollution consistently missed opportunities to raise environmental health literacy.

\section{Conclusions}


47 Although air pollution levels are high and continue to rise at alarming rates, our findings suggest

48 that news media reporting is not conducive to raising environmental health literacy. Public health

49 advocates and health promotion experts must develop more effective strategies for disseminating

50 information about the health risks of air pollution, balancing the need for recognizing the

51 structural causes of poor air quality and the actions individuals and communities can take to

52 reduce air pollution related morbidity and mortality. National and local news media may be

53 useful partners for such dissemination.

54

55 Keywords: Air pollution, Environment health, Public health, Newspapers, Environmental health

56 literacy, Health promotion, Health communication, Efficacy, Risk communication, Advocacy

57 


\section{Background}

59 Air pollution is the single largest environmental health risk and one of the largest global risk

60 factors $[1,2]$, with outdoor air pollution estimated to be responsible for almost 8 percent of total

61 global deaths [3]. To manage individual risk from air pollution, individuals need to be aware

62 when air quality is poor [4-6]. The primary official forms of communication about air pollution

63 to achieve this goal are air quality advisories; however, the information environment is much

64 broader than targeted campaigns [7]. The broad public information environment is an important

65 determinant of knowledge, attitudes, and other cognitive and emotional determinants of behavior

$66[8-10]$ and should be investigated beyond air quality advisories. Especially since awareness of

67 air quality advisories often does not lead to behavior change, and air quality advisories are

68

69

70

71

72

73

74

among the least reported sources of information for air pollution [4, 11]. Research has found that media, together with sensory and health cures, are the primary sources of information in air polluted regions $[11,12]$. Information found in the media can increase awareness environmental risks, such as air pollution, and help individuals with processes that lead to risk reducing behavior $[13,14]$. Moreover, consistent with an ecological approach to health [2], recent research in environmental health literacy argues that messaging must move beyond exclusively focusing on individual behavior change to include strategies that empower individuals to mobilize for the control of environmental exposures [15-17]. Media influence which issues the public are exposed to and thereby set the public agenda [18]. Agenda-setting research has furthermore shown that news coverage plays a role in shaping public opinion and the local policy agenda, and that this role is more prominent for local level news [19].

The current research explores how air pollution is covered in news media. The extended parallel process model (EPPM) [20] that is commonly used to explain how individuals process 
81 health messages, proposes that for an individual to accept a message and change behavior, two appraisal steps are necessary. First, an individual needs to perceive a threat to themselves that warrants action, and second an individual needs to perceive themselves able to avert the threat [20]. For an individual to rake risk reducing action, they need to know both about the risk as well as effective actions they can take to reduce risk We therefore conducted a content analysis of newspapers and examined how individuals might process media messages by analyzing how much health risk (threat) and information about precautionary measures (efficacy information) air pollution coverage contains. Effective precautionary measures individuals can take are: staying indoors, limiting physical activity, or using air filters to clean indoor air during severe air pollution days [6]. In addition to examining health risk and information about precautionary measures, we examined the potential influence of journalists' information sources on the framing of air pollution. The manner in which issues are presented or framed in the media affects the perceptions of the public [21]. Media coverage of environmental issues has been critiqued for lacking substance, adequate coverage, and lack of potential solutions [22, 23]. The choice of source for a story influences how a story is framed, the substance that is included, and which solutions are provided [24].

National news was compared with local news from California's San Joaquin Valley (SJV). The SJV is a rural and economically disadvantaged region that lacks resources and access to address environmental and public health threats $[25,26]$. Moreover, this region is one of the worst air polluted areas in the US [27]. Latino, low-income, and less-educated populations which are overrepresented in the SJV- have less access to health information $[28,29]$. For minorities that suffer from this lack of access, news media are the primary and trusted sources of health information [30]. News media, especially local news media, may be a particularly 


\section{Methods}

\section{Study sample}

important source of information for residents of the SJV, since the lack of resources and the geographically-dispersed nature of rural areas such as the SJV make it hard to reach the population through other channels.

By assessing which essential risk reducing information is missing in newspaper coverage, and which messages individuals are exposed to, health promotion efforts can be tailored to take the revealed information into account, creating more effective campaigns.

$$
\text { Two national newspapers, the New York Times and the Washington Post, were selected to }
$$
represent the national-level discourse of air pollution in the media. Two newspapers from the

SJV, the Fresno Bee and the Bakersfield Californian, represented local news about air pollution. The New York Times and the Washington Post have high circulation and influential status and are considered to be agenda setters for other media in the US [18]. Both the Fresno Bee and the Bakersfield Californian are among the highest circulating papers in California's air polluted San Joaquin Valley and are the hometown papers of the two most polluted cities in the US [27].

\section{News coverage selection}

The data for this study were news stories about air pollution published in the four newspapers during the five-year period 2011-2015. News stories were obtained from the Lexis-Nexis database for the two national newspapers and the Newsbank World News database for the two local newspapers. Following procedures described by Stryker and colleagues [31], a search term was constructed. News stories about air pollution were operationalized as needing to include air 
127 pollution content in the title and/or first three paragraphs. The following search term was used to 128 collect the sample: ATLEAST1(air quality or air pollution) AND (air pollution or air quality or 129 clean air or dirty air or polluted air or smok! or fume! or cloud or gas! or exhaust! or vapor or 130 inhale! or breathe! or respir! or emission! or smog or ozone) in any of the first three paragraphs

131 (HLEAD was used in Lexis-Nexis to automate this process). To keep our sample size 132 manageable while obtaining an accurate estimate of the population, a constructed week sampling 133 approach was used. Constructed week sampling is a stratified random sampling technique that is 134 preferred to simple random sampling as it accounts for variation of news content over a seven135 day news week [32]. The current study sampled 6 constructed weeks for each of the five years in 136 which news stories (both national as well as local) were collected for a total of 30 constructed 137 weeks, yielding a total of 276 articles.

140 We measured threat, efficacy information, and information sources. All measures were 141 dichotomous items. Stories were coded a threat if an article included any information about air 142 pollution being adverse to health. Efficacy was coded if the article included any information 143 about the precautionary measures an individual can take to reduce risk from air pollution. The 144 coding of efficacy information included an additional stage. If an article included efficacy 145 information, the nature of the efficacy information was investigated to see if the efficacy 146 information included any of the effective precautionary measures individuals can take: staying 147 indoors, limiting physical activity, or using air filters to clean indoor air during severe air 148 pollution days [6]. To examine which sources were utilized in the articles about air pollution, 5 types of sources were coded. The source typology was based on work by Brossard and 
150

151

152

153

154

155

156

157

158

159

160

161

162

163

164

165

166

167

168

169

170

171

172

colleagues [33] and included: academics and scientists, non-expert/citizen, business/industry groups, governmental sources and health, and environmental advocacy groups. All articles were analyzed to see if any of these sources were utilized. It was possible to code for multiple sources per article.

Once the coding instrument was developed, two coders were randomly assigned three sections $(\mathrm{N}=109,39.5 \%$ of total sample) to code. Cohen's kappa showed substantial agreement (mean $\mathrm{k}=.68)$ [34]. Initial interrater reliability was below the threshold set a priori $(\mathrm{k}<.7)$ for three codes classifying cited sources: "non-expert/citizen sources”, "business/industry groups", and "health and advocacy groups". To achieve a higher level of reliability, the two coders double coded all articles for these codes and conducted consensus meetings afterwards. As a result, the final average Cohen's kappa increased to high agreement (mean $\mathrm{k}=.85)$ [34]. The remaining years of air pollution news articles were randomly distributed and coded independently by the two coders.

\section{Data analysis}

To compare differences between local and national newspapers, chi-square independence tests were conducted. Fisher's exact test was used in case the expected cell count was less than 5. All descriptive statistics, reliability, and chi-square tests and were performed with IBM SPSS Statistics 24.0.

\section{Results}

A total of 276 articles met our selection criteria and were read and analyzed: 162 national newspaper articles and 114 local newspaper articles. The New York Times $(\mathrm{n}=98)$ accounted for 
173 the majority of the coverage, followed by the Washington Post $(\mathrm{n}=64)$, the Bakersfield

174 Californian $(\mathrm{n}=61)$, and the Fresno Bee $(\mathrm{n}=53)$. There was no significant difference in the

175 number of articles reporting about air pollution between local and national newspapers $\left(\mathrm{X}^{2}=\right.$ $176 \quad 3.732, \mathrm{P}=.053)$.

\section{Threat and efficacy}

179 Threat information (39.9\%) was reported more than efficacy information $(7.6 \%)$ in the combined 180 sample $\left(\mathrm{X}^{2}=34.626, \mathrm{P}=.001\right)$. Threat was reported more frequently compared to efficacy in 181 both local newspapers $\left(\mathrm{X}^{2}=15.039, \mathrm{P}<.001\right)$ and national newspapers $\left(\mathrm{X}^{2}=18.935, \mathrm{P}<.001\right)$.

182 No newspaper reported efficacy information without reporting threat information (Fig. 1). Table 1831 compares threat and efficacy information for local and national newspapers. When comparing 184 local newspapers with national newspapers, local newspapers reported more threat information $185(44.7 \%)$ compared to national newspapers (36.4\%). However, this difference was not statistically 186 significant $\left(\mathrm{X}^{2}=1.931, \mathrm{P}=.165\right)$. Similarly, no significant difference $\left(\mathrm{X}^{2}=1.118, \mathrm{P}=.209\right)$ was

187 found for the reporting of efficacy information in local newspapers (13.0\%) compared to national 188 newspapers $(9.6 \%)$. When reporting recommended efficacy information, no significant 189 differences were found for the individual risk reducing behavior "stay indoors" $\left(\mathrm{X}^{2}=.885, \mathrm{P}=\right.$ $190.347)$, and "use of air filters" $\left(\mathrm{X}^{2}=.953, \mathrm{P}=.652\right)$. However, local newspapers did report more 191 on "limiting physical activity" compared to national newspapers $\left(\mathrm{X}^{2}=5.105, \mathrm{P}=.036\right)$.

\section{Information sources}

193 Reporters primarily used governmental sources, followed by business/industry groups, health 194 and environmental advocacy groups, academics and scientist, and non-expert/citizen sources 195 (Fig. 2). A similar order was found for national newspapers. Local newspapers also used 
196

197

198

199

200

201

202

203

204

205

206

207

208

209

210

211

212

213

214

215

216

217

218

governmental sources primarily, followed by business/industry sources, and health and environmental advocacy groups. Although they used more non-expert citizen sources compared to academic sources. National newspapers used disproportionally more information sources in their articles compared to local newspapers. As can be seen in Table 2, national newspapers utilized significantly more academic and scientist sources $\left(\mathrm{X}^{2}=21.881, \mathrm{P}<.001\right)$, business/industry groups $\left(\mathrm{X}^{2}=28.189, \mathrm{P}<.001\right)$, governmental sources $\left(\mathrm{X}^{2}=26.089, \mathrm{P}<.001\right)$, and health and environmental advocacy groups $\left(\mathrm{X}^{2}=16.680, \mathrm{P}<.001\right)$. No significant differences were found in the use of non-expert/citizen as information sources for reporters $\left(\mathrm{X}^{2}=\right.$ $.004, \mathrm{P}=.950)$.

\section{Discussion}

Although exposure to air pollution is one of the largest global risk factors [1], and rising at alarming rates [2], it is often overlooked in health promotion research [35] and practice. The present study is the first to look at the nature of air pollution reporting in the media, exploring factors in news reporting about air pollution that might affect individual risk reducing behavior. Similarly to other content analyses analyzing newspaper reporting of other health issues [36-39], we found that air pollution stories contained more threat information than efficacy information. It is important that newspapers report about the threat of air pollution on health, as this informs the public on the need for action. However, by not providing any information on what to do to reduce the introduced threat, undesirable side effects can happen. The EPPM [20] posits that when threat information is high and efficacy information is low, individuals will manifest a maladaptive coping response such as denial and avoidance of information [40]. While results can differ for individuals, as individual differences including prior experiences, culture, and 

221 behavior.

222

personality influence appraisal of threat and efficacy [20], our results suggest that current reporting about air pollution in newspapers is not conducive to promotion of risk reducing

This study found that news reporting about air pollution lacked information about effective precautionary measures that individuals can take. Local newspapers in the SJV did not reported significantly more about air pollution, threat, and efficacy compared to national newspapers, despite being located in one of the worst air polluted areas in the US, and despite the fact that air pollution is a major concern for residents of the valley [41, 42]. The results are not entirely surprising, as there is research suggesting that news stories about health are scarce [43]. In addition, this relative absence of news stories about air pollution is in line with a recent study analyzing local news reporting about health in the SJV, which also found limited coverage of air pollution [28]. However, the lack of efficacy in local publications is alarming as public information sources in the region have a similar deficiency [17], making it plausible that residents in the SJV have insufficient information available necessary to protect themselves from the adverse effects of air pollution. Public health advocates and health promotion experts must recognize the need to balance the structural causes of poor air quality and the actions individuals and communities can take to reduce air pollution related morbidity and mortality. It is necessary to develop more effective strategies for disseminating information about the health risks of air pollution. National and local news media may be useful partners for such dissemination, as media play a vital role in public understanding of environmental risks [44]. Similar to content analyses of other environmental issues [23, 33], both local and national newspapers over-relied on governmental sources. The high reliance on governmental sources is concerning as they are likely to present established views [23]. Moreover, the high reliance on 
242 governmental sources is particularly concerning in the current political climate as governmental 243 agencies are acting in conflict with their goals. For example, the agency in charge of mitigating 244 air pollution, is advocating for relaxation of the Clean Air Act legislation [45]. The relative lack 245 of sources that might present unconventional views limits the range of concerns and solutions 246 presented in the news. This has implications for the policy changes necessary to reduce air 247 pollution (health risk). For instance, changes in tobacco policy benefited from the voices of 248 diverse groups and organizations to established public perceptions necessary to mobilize change. 249 Collaboration in news media campaigns to increase media attention to diverse voices is therefore 250 recommended [46]. Non-governmental groups such as health and environmental groups and 251 academics and scientists should consider similar tactics to voice their concerns about air 252 pollution. Academics and scientist sources were present in less than a quarter of the articles. The 253 primary reliance of air pollution reporting on sources that might not be impartial and lack 254 expertise might not be conductive to the understanding of air pollution by the general audience.

255 Future studies should investigate if these sources cause environmental health literacy 256 misinformation and misperceptions.

257 Despite the strengths, this study suffers from some limitations. To begin, only a select 258 number of newspapers were included in the current study. It is possible that a selection of 259 different newspapers would reveal different patterns. Similarly, a selection of different news 260 sources (e.g., online news or broadcast) could show different results. However, we are 261 reasonably confident that this is unlikely because newspapers -and in particular widespread 262 national newspapers such as the national newspapers (i.e. New York Times and Washington Post) 263 utilized in this content analysis- are agenda setters for other media sources [9]. Additionally, our 264 coding for threat and efficacy information were simple binary codes. Coding therefore ignores 
any nuanced tones and implications that potentially exist in the news story. Lastly, coverage patterns could have changed since the time of the study (2011-2015), as developments such as the WHO campaign [47] to mobilize people to bring air pollution to safe levels or the 2016 presidential election and resulting changes at the EPA could have influenced the coverage. For example, the salient new efforts made by the WHO to convince the public and policy makers of the disastrous effects of air pollution by branding it "the silent killer" might have increased the amount of threat reporting in newspapers.

\section{Conclusions}

The findings of this study suggest that reporting about air pollution in newspapers is not conducive to risk reducing behavior. Newspapers mostly fail to report on the health impacts air pollution can have. Moreover, there needs to be a better balance between threat and efficacy information -especially effective precautionary measures that individuals can take- in the reporting about air pollution. Given the large impact air pollution has on the SJV and the importance of local news on public opinion and the local policy agenda, more health promoting news stories about air pollution would be beneficial. In addition, health promotion efforts should consider the information in the media environment and develop strategies to enhance the air pollution information environment. Health promotion efforts, such as the breath air campaign by the WHO, might mobilize people into action by increasing the amount of threat information available. However, to neutralize potential undesirable effects, campaigns would do well to provide efficacy information on how to reduce individual risk from air pollution. The current reliance on conventional sources of information by journalists might forestall the understanding of complex issues such as air pollution. Air pollution reporting would benefit from more diverse, 
288 expert, and impartial sources. News coverage of air pollution consistently missed opportunities

289 to raise environmental health literacy. Health promotion efforts should consider using news

290 media strategically to increase environmental health literacy.

291 


\section{Abbreviations}

EPPM: Extended Parallel Process model SJV: San Joaquin Valley

\section{Declarations}

\section{Acknowledgments}

299

We thank J. Wallander and A.V. Song for their expert advice. We thank Nadia Alazzeh, Jacqueline Diaz, Kimberly Huynh, Natalie Pena Marquez, and Yesenia Villa for their coding efforts.

\section{Funding}

This project was supported by the US Agency for International Development through a grant from the UC Berkeley Development Impact Lab.

\section{Availability of data and materials}

The datasets used and/or analyzed during the current study are available from the corresponding author on reasonable request.

\section{Authors' contributions}

SR contributed to study design, data collection, analyses, and manuscript preparation. ASR contributed to study design and manuscript preparation. All authors read and approved the final manuscript.

\section{Ethics approval and consent to participate}

Not applicable.

\section{Consent for publication}

Not applicable.

\section{Competing interests}

Not applicable. 


\section{References}

1. Forouzanfar MH, Alexander L, Anderson HR, Bachman VF, Biryukov S, Brauer M, et al. Global, regional, and national comparative risk assessment of 79 behavioural, environmental and occupational, and metabolic risks or clusters of risks in 188 countries, 1990-2013: a systematic analysis for the Global Burden of Disease Study 2013. The Lancet. 2015;386:2287-323.

2. Landrigan PJ, Fuller R, Acosta NJR, Adeyi O, Arnold R, Basu N (Nil), et al. The Lancet Commission on pollution and health. The Lancet. 2017;0. doi:10.1016/S0140-6736(17)32345-0.

3. WHO. Mortality and burden of disease from ambient air pollution. Global Health Observatory (GHO) data. 2019. https://www.who.int/gho/phe/outdoor_air_pollution/burden/en/.

4. Borbet TC, Gladson LA, Cromar KR. Assessing air quality index awareness and use in Mexico City. BMC Public Health. 2018;18:538.

5. Cairncross EK, John J, Zunckel M. A novel air pollution index based on the relative risk of daily mortality associated with short-term exposure to common air pollutants. Atmos Environ. 2007;41:844254.

6. Laumbach R, Meng Q, Kipen $\mathrm{H}$. What can individuals do to reduce personal health risks from air pollution? J Thorac Dis. 2015;7:96-107.

7. Moldovan-Johnson M, Tan ASL, Hornik RC. Navigating the Cancer Information Environment: The Reciprocal Relationship Between Patient-Clinician Information Engagement and Information Seeking from Nonmedical Sources. Health Commun. 2014;29:974-83.

8. Leask J, Hooker C, King C. Media coverage of health issues and how to work more effectively with journalists: a qualitative study. BMC Public Health. 2010;10:535.

9. Niederdeppe J, Froch DL, Hornik RC. Cancer News Coverage and Information Seeking. J Health Commun. 2008;13:181-99.

10. Viswanath K. The communications revolution and cancer control. Nat Rev Cancer. 2005;5:828-35.

11. Brown P, Cameron L, Cisneros R, Cox R, Gaab E, Gonzalez M, et al. Latino and Non-Latino Perceptions of the Air Quality in California's San Joaquin Valley. Int J Environ Res Public Health. 2016;13:1242.

12. Johnson BB. Experience with Urban Air Pollution in Paterson, New Jersey and Implications for Air Pollution Communication. Risk Anal. 2012;32:39-53.

13. Mello S. Media Coverage of Toxic Risks: A Content Analysis of Pediatric Environmental Health Information Available to New and Expecting Mothers. Health Commun. 2015;30:1245-55.

14. Slovic P. Perception of risk. Science. 1987;236:280-5.

15. Finn S, O'Fallon L. The Emergence of Environmental Health Literacy_From Its Roots to Its Future Potential. Environ Health Perspect. 2017;125:495-501. 
16. Gray KM. From Content Knowledge to Community Change: A Review of Representations of Environmental Health Literacy. Int J Environ Res Public Health. 2018;15. doi:10.3390/ijerph15030466.

17. Ramírez AS, Ramondt S, Bogart KV, Perez-Zuniga R. Public Awareness of Air Pollution and Health Threats: Challenges and Opportunities for Communication Strategies To Improve Environmental Health Literacy. J Health Commun. 2019;24:75-83.

18. McCombs ME. Setting the agenda: The mass media and public opinion. Malden, MA: Blackwell; 2004.

19. Nagler RH, Bigman CA, Ramanadhan S, Ramamurthi D, Viswanath K. Prevalence and Framing of Health Disparities in Local Print News: Implications for Multilevel Interventions to Address Cancer Inequalities. Cancer Epidemiol Prev Biomark. 2016;25:603-12.

20. Witte K. Putting the fear back into fear appeals: The extended parallel process model. Commun Monogr. 1992;59:329-49.

21. Scheufele DA, Shanahan J, Kim S-H. Who Cares about Local Politics? Media Influences on Local Political Involvement, Issue Awareness, and Attitude Strength: Journal Mass Commun Q. 2016. doi:10.1177/107769900207900211.

22. Boykoff MT, Boykoff JM. Climate change and journalistic norms: A case-study of US mass-media coverage. Geoforum. 2007;38:1190-204.

23. Zamith R, Pinto J, Villar ME. Constructing Climate Change in the Americas An Analysis of News Coverage in U.S. and South American Newspapers. Sci Commun. 2013;35:334-57.

24. Liebler CM, Bendix J. Old-Growth Forests on Network News: News Sources and the Framing of An Environmental Controversy. Journal Mass Commun Q. 1996;73:53-65.

25. Abood M. San Joaquin Valley Fair Housing and Equity Assessment. 2014. http://www.frbsf.org/community-development/files/SJV-Fair-Housing-and-Equity-Assessment.pdf. Accessed 12 Apr 2016.

26. Taylor JE, Martin PL. The new rural poverty: Central Valley evolving into patchwork of poverty and prosperity. Calif Agric. 2000;54:26-32.

27. State of the air. State of the Air 2019. Chicago, IL.: American Lung Association; 2019. https:/www.lung.org/assets/documents/healthy-air/state-of-the-air/sota-2019-full.pdf.

28. Ramírez AS, Estrada E, Ruiz A. Mapping the Health Information Landscape in a Rural, Culturally Diverse Region: Implications for Interventions to Reduce Information Inequality. J Prim Prev. 2017;:118.

29. Viswanath K, Ackerson LK. Race, Ethnicity, Language, Social Class, and Health Communication Inequalities: A Nationally-Representative Cross-Sectional Study. PLoS ONE. 2011;6:e14550.

30. Livingston G, Minushkin S, Cohn D. Hispanics and healthcare in the United States: Access, information and knowledge. 2008. http://pewhispanic.org/files/reports/91.pdf. 
31. Stryker JE, Wray RJ, Hornik RC, Yanovitzky I. Validation of Database Search Terms for Content Analysis: The Case of Cancer News Coverage. Journal Mass Commun Q. 2006;83:413-30.

32. Luke DA, Caburnay CA, Cohen EL. How Much Is Enough? New Recommendations for Using Constructed Week Sampling in Newspaper Content Analysis of Health Stories. Commun Methods Meas. 2011;5:76-91.

33. Brossard D, Shanahan J, McComas K. Are Issue-Cycles Culturally Constructed? A Comparison of French and American Coverage of Global Climate Change. Mass Commun Soc. 2004;7:359-77.

34. Neuendorf KA. The content analysis guidebook. Thousand Oaks, CA: Sage; 2002.

35. Howze EH, Baldwin GT, Kegler MC. Environmental Health Promotion: Bridging Traditional Environmental Health and Health Promotion. Health Educ Behav. 2004;31:429-40.

36. Hart PS, Feldman L. Threat Without Efficacy? Climate Change on U.S. Network News. Sci Commun. 2014;36:325-51.

37. He S, Shen Q, Yin X, Xu L, Lan X. Newspaper coverage of tobacco issues: an analysis of print news in Chinese cities, 2008-2011. Tob Control. 2014;23:345-52.

38. Jensen JD, Moriarty CM, Hurley RJ, Stryker JE. Making Sense of Cancer News Coverage Trends: A Comparison of Three Comprehensive Content Analyses. J Health Commun. 2010;15:136-51.

39. Shim M, Kim Y-C, Kye SY, Park K. News Portrayal of Cancer: Content Analysis of Threat and Efficacy by Cancer Type and Comparison with Incidence and Mortality in Korea. J Korean Med Sci. 2016;31:1231-8.

40. Witte K, Allen M. A Meta-Analysis of Fear Appeals: Implications for Effective Public Health Campaigns. Health Educ Behav. 2000;27:591-615.

41. Cisneros R, Brown P, Cameron L, Gaab E, Gonzalez M, Ramondt S, et al. Understanding Public Views about Air Quality and Air Pollution Sources in the San Joaquin Valley, California. J Environ Public Health. 2017;2017:e4535142.

42. Meng Y-Y, Rull RP, Wilhelm M, Lombardi C, Balmes J, Ritz B. Outdoor air pollution and uncontrolled asthma in the San Joaquin Valley, California. J Epidemiol Community Health. 2010;64:1427.

43. Caburnay CA, Kreuter MW, Luke DA, Logan RA, Jacobsen HA, Reddy VC, et al. The News on Health Behavior: Coverage of Diet, Activity, and Tobacco in Local Newspapers. Health Educ Behav. 2003;30:709-22.

44. Fitzpatrick-Lewis D, Yost J, Ciliska D, Krishnaratne S. Communication about environmental health risks: A systematic review. Environ Health. 2010;9:67.

45. Tabuchi H. Calling Car Pollution Standards 'Too High,' E.P.A. Sets Up Fight With California. The New York Times. 2018. https://www.nytimes.com/2018/04/02/climate/trump-auto-emissions-rules.html. Accessed 3 May 2018. 
46. Eliott J, Forster AJ, McDonough J, Bowd K, Crabb S. An examination of Australian newspaper coverage of the link between alcohol and cancer 2005 to 2013. BMC Public Health. 2017;18:47.

430 47. BreatheLife. BreatheLife. 2018. http://breathelife2030.org/. Accessed 17 Apr 2018.

431 
Figures

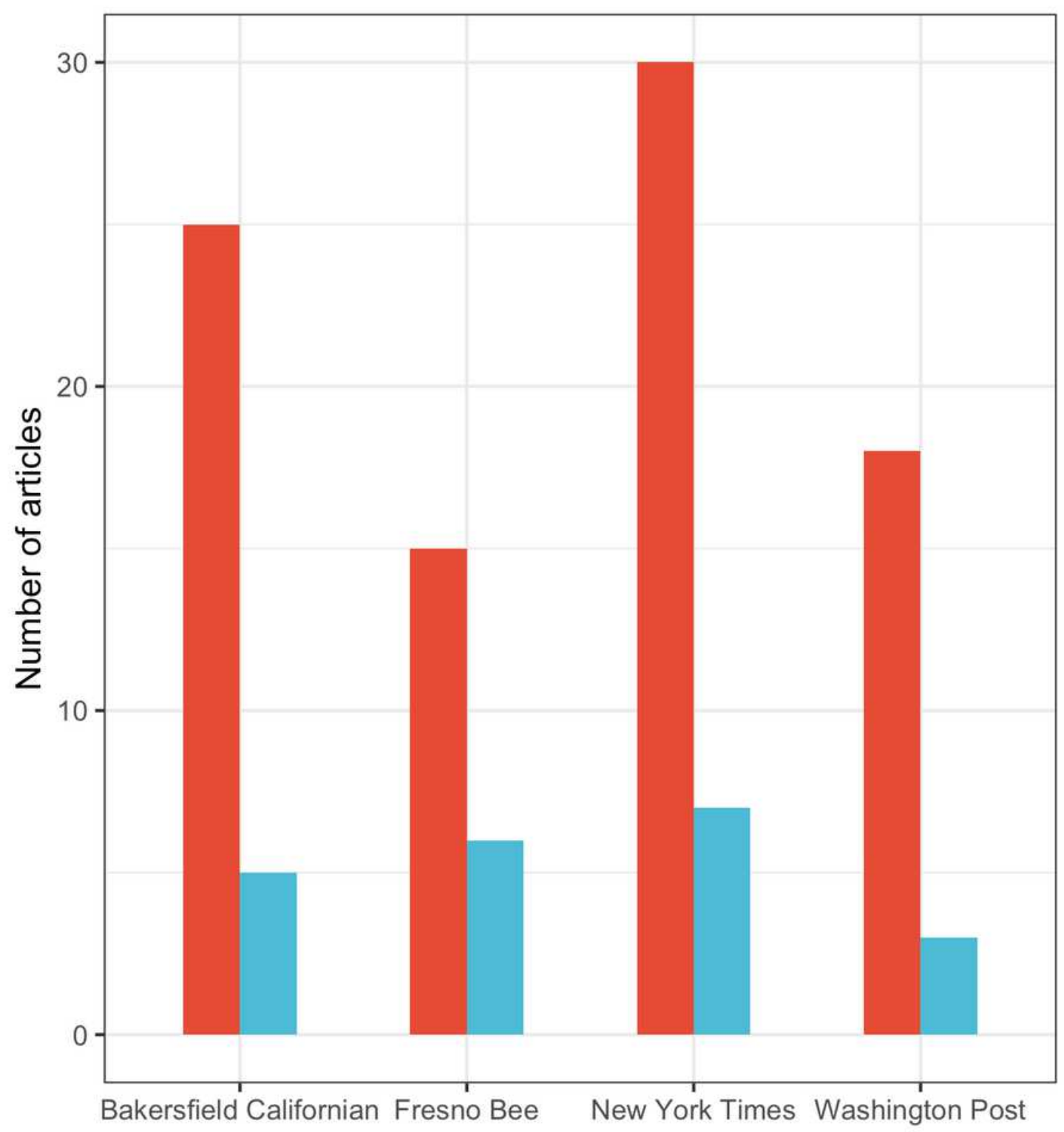

Threat

Threat \& Efficacy

Figure 1

Threat information (39.9\%) was reported more than efficacy information $(7.6 \%)$ in the combined sample $(X 2=34.626, P=.001)$. Threat was reported more frequently compared to efficacy in both local newspapers $(X 2=15.039, P<.001)$ and national newspapers $(X 2=18.935, P<.001)$. No newspaper reported efficacy information without reporting threat information. 


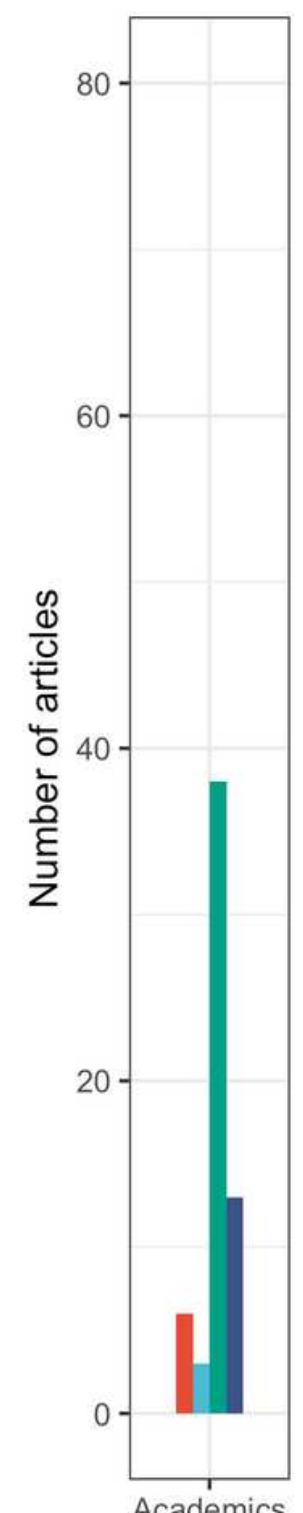

Academics
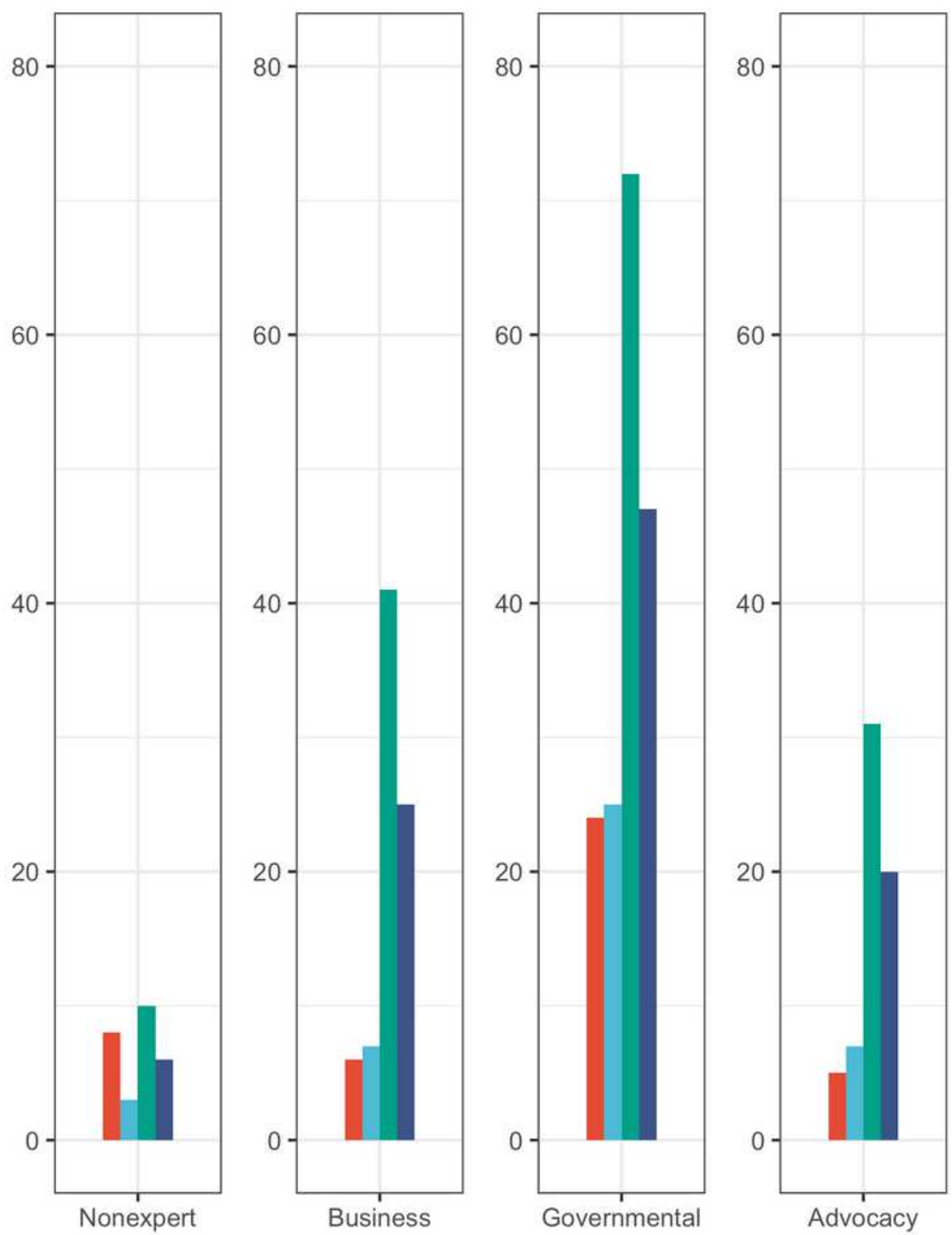

Bakersfield Californian Fresno Bee New York Times Washington Post

\section{Figure 2}

Reporters primarily used governmental sources, followed by business/industry groups, health and environmental advocacy groups, academics and scientist, and non-expert/citizen sources. A similar order was found for national newspapers. Local newspapers also used governmental sources primarily, followed by business/industry sources, and health and environmental advocacy groups. Although they used more non-expert citizen sources compared to academic sources. National newspapers used disproportionally more information sources in their articles compared to local newspapers. 